\title{
Mônadas sobre mulheres indígenas na Universidade
}

\section{Moments about indigenous women at University}

\author{
Tatiana de Oliveira Santana ${ }^{1}$ \\ Elison Antonio Paim ${ }^{2}$
}

Resumo: Utilizando-se de suportes teórico-metodológicos com fontes orais, numa acepção benjaminiana de construção de conhecimentos históricos a partir das narrativas em mônadas, objetivamos apresentar as experiências, memórias e rememorações sobre o espaço acadêmico a partir do período recente das políticas afirmativas de quatro mulheres, pertencentes a povos originários distintos, na região do sul e sudeste do Pará, discentes de cursos de graduação da Unifesspa, desenvolvendo uma tessitura dialógica entre o filósofo porto-riquenho Nelson Maldonaro Torres, o sociólogo venezuelano Edgardo Lander e a linguísta estadounidense equatoriana Catharine Walsh.

Palavras-chave: Mônadas, Universidade, Narrativas Indígenas.

\begin{abstract}
Using theoretical and methodological supports with oral sources, in a Benjaminian sense of construction of historical knowledge from narratives in monads, we present the experiences, memories and recollections about the academic space from the recent period of the affirmative policies of four women from different native peoples, in the region south and southeast of Pará, undergraduate students of Unifesspa, developing a dialogue between Puerto Rican philosopher Nelson Maldonaro Torres, Venezuelan sociologist Edgardo Lander,
\end{abstract}

Keywords: Monads, University, Indigenous Narratives.

\section{Narrativas em montagens monadológicas}

Apresentamos, neste artigo, parte da pesquisa denominada Narrativas femininas Guajajara e Akrãtikatêjê no ensino superior, desenvolvida no Programa de Pós Graduação em Educação da Universidade Federal de Santa Catarina (UFSC) no ano de 2017.

A presença de povos originários nos cursos de graduação e a construção de politicas afirmativas indígenas, nas universidades públicas brasileira, vem aumentando

\footnotetext{
${ }^{1}$ Tatiana de Oliveira Santana, Graduada em Pedagogia e Especialista em Educação do Campo, Cultura e Letramento pela Universidade Federal do Pará. Mestre pelo Programa de Educação na linha História e Sociologia da educação na Universidade Federal de Santa Catarina (UFSC). Tel.: (94) 99119 8378. E-mail: tati_ubuntu@hotmail.com.

${ }^{2}$ Prof. Dr. Elison Antonio Paim, Professor permanente do Programa de Pós-Graduação em Educação (PPGE), Mestrado Profissional em Ensino de História (Profhistória/UFSC) e de Estágio Supervisionado em História da Universidade Federal de Santa Catarina (UFSC). E-mail: elison0406@gmail.com.
} 
consideravelmente, e a este fato nos interrogamos: quais são as experiências de ensino superior que os povos originários nos contam? Quais são as suas memórias dessas experiências? Qual o significado dessas experiências para eles/elas?

Utilizando-nos de suportes teórico-metodológicos com fontes orais, trabalhamos com quatro mulheres, pertencentes a povos originários ${ }^{1} \operatorname{distintos}^{2}$, na região do sul e sudeste do Pará, discentes de cursos de graduação da Universidade Federal do Sul e Sudeste do Pará (UNIFESSPA) ${ }^{3}$, a partir do período recente das políticas afirmativas, tendo como objetivo analisar suas experiências e memórias trazidas/vividas no âmbito acadêmico.

As experiências narradas, que utilizamos na pesquisa, foram desenvolvidas em encontros, que denominamos de círculos narrativos femininos, feitos com entrevistas semi estruturadas e rodas de dialógos sobre vida escolar, mulher indígena, entrada, permanência e planos de futuro após universidade. Após a gravação, as narrativas foram ouvidas, transcritas e feita a montagem das mônadas. As mônadas foram construídas em formato de mosaico, de acordo com a perspectiva monadológica de Walter Benjamin. As narrativas femininas indígenas trazem elementos para discussão sobre os desafios, permanência e protagonismo feminino indígena na universidade, e, dessa forma, problematizam a relação do ser, saber, de gênero pautado na interculturalidade como possibilidade real de diálogo entre saberes e fazeres. ${ }^{4}$

A tessitura monadológica permite ao leitor conhecer as mulheres e suas experiências por elas mesmas. Entendendo que elas também falam aos leitores e estes fazem suas leituras, poderiam fazer suas próprias interpretações, para além do analisado, tendo cada leitor suas impressões, e podem ser interpretadas de diferentes formas, dependendo do lugar, tempo e campo que se ocupa.

Benjamin (2012) propõe a reflexão sobre a redução das experiências comunicáveis e, com isso, a promoção de novas barbáries, causando a perda da memória, identidade e parte da história dos que são invisibilizados, dizimados dos processos de construção de uma nova época de experiências de modernização e cultura do vidro.

Portanto, o filosofo alemão, quando, no exercício de rememoração de seu passado a partir do presente, escreve as mônadas sobre sua infância no texto intitulado Infância em Berlim, auxiliando-nos no trabalho com essas oralidades de forma respeitosa.

Logo, o trabalho artesanal monadológico do qual Benjamin é ator, ao propor que a mônada contém a idéia do mundo, o dizível por ela mesma, representa o fenômeno das suas ideias sobre o estabelecido, sobre o experienciado (BENJAMIN, 2011). 
Metodologicamente nos inspiramos nesse autor e fomos compondo as mônadas sobre a universidade pelas memórias das mulheres.

Dessa forma, trazemos as narrativas em montagens monadológicas por entendêlas, à luz do pensamento de Benjamin (2007, p. 499, 500, 503), como conhecimentos em lampejos, o texto como trovão que ressoará por muito tempo, montando essa tessitura de várias mãos e experiências "sem a necessidade de usar aspas", e erguendo as construções "a partir dos minúsculos, recortados com clareza e precisão". Portanto, as narrativas sobre a experiência na universidade falam por si, trazendo elementos para pensar sobre esse presente histórico na própria voz de suas protagonistas. Nesse sentido, nós, pesquisadores, interferimos o mínimo possível nas narrativas e também não procuramos trabalhar numa perspectiva que suscitasse nossa interferência fazendo análises.

Salientamos que fizemos a opção política pelo uso dos nomes das participantes da pesquisa, na compreensão de que "trabalhar com narrativas de memórias, numa perspectiva de diálogo, possibilita que os narradores percebam que muitas das respostas que buscam estão presentes em suas experiências vividas e nas memórias" (PAIM, 2013a, p. 97).

Dessa forma, ao refletir sobre a história dos grupos excluídos historicamente da sociedade, os que sempre foram invisibilizados e homogeneizados devido as lógicas eurocêntricas e de dominação e apagamento dos diversos conhecimentos e culturas, os conceitos do filósofo alemão Walter Benjamin sobre história, experiência e memória, mesmo sendo um autor europeu, nos dá ferramentas de interpretações diferenciadas em relação a estes grupos invisibilizados.

$\mathrm{Na}$ relação com a metodologia monadológica de Benjamin tomamos como fundamentação para o diálogo alguns conceitos de autores e autoras decoloniais como o filósofo porto-riquenho Nelson Maldonaro-Torres, o sociólogo venezuelano Edgardo Lander, a linguísta estadounidense equatoriana Catharine Walsh.

No desenvolvimento do presente artigo, apresentamos narrativas em forma de mônadas de mulheres indígenas, carregadas de experiências de quem vive a universidade. E, por acreditarmos ser necessária uma troca entre saberes com diálogos reflexivos e respeitosos, os quais podem provocar mudanças perante situações de violência, de desrespeito ao outro, em detrimento de imposição de um saber que se coloca hierarquizado e único, desenvolvemos uma análise pela ótica pedagógica intercultural, finalizando com considerações finais que buscam possíveis reflexões. 
Destacamos que não esgotamos as possibilidades de analises das mônadas; levantamos algumas reflexões em diálogos com as experiencias narradas ao trazermos o silenciado, o miúdo, que causam rupturas em práticas de produção de conhecimento que são tecidos na linguagem e que não se limitam a somente uma possibilidade de interpretação, de tempo, de local (ROSA, 2009).

\section{Mônadas sobre a experiência na universidade}

\section{Cada um tem um saber}

[...] o povo indígena cada um tem um saber, assim como nos povo Akrakikateje tem esse dom essa sabedoria. [...] estudar não é para todos [...] por isso que eu to pedindo aqui dentro, eu quero professor de qualidade, qualificado, pra preparar meu povo, pra que quando ele for pra uma faculdade, ele saiba onde ele está estudando, ele vai ter visão, ele vai falar. [...] o estudo, a sabedoria não vai desaculturar vocês, não vai tirar nossa cultura, porque eu falo assim: Com conhecimento que a gente tem, com oficinas que tem dentro da comunidade, você aprende, mais voltado pra comunidade, voltado com pensamento no povo, um olhar diferenciado pro nosso povo (Kátia).

A mônada da cacica "Cada um tem um saber", fala das diferenças entre os saberes de cada povo e a reflexão de que embora a universidade não seja para todos, são portadores de saberes, que pela lógica ocidentalizada e europeia que invisibiliza outros conhecimentos, são diferentes, mesmo estando na universidade e existe uma grande responsabilidade em dialogar com esses saberes sem perder suas identidades.

Nesse sentido, sua narrativa nos remete para o dialogo com Catherine Walsh (2009) ao defender no campo educacional a necessidade de uma abordagem da interculturalidade crítica. Diferente da interculturalidade funcional, que reconhece outras culturas, outros saberes, mas não modifica a estrutura social, a interculturalidade crítica prioriza a problematização da epistemologia moderna ocidental e busca desestruturar a hierarquia entre saberes. A autora, preconiza o reconhecimento e respeito à diversidade cultural, que, pelo discurso neoliberal, se converteu em uma nova estratégia de dominação, pautada no multiculturalismo, cuja ferramenta conceitual, a interculturalidade "funcional", ao invés de diferenciar, integra os grupos historicamente excluídos a fim de impulsionar os imperativos econômicos do modelo neoliberal de acumulação capitalista, deixando de contribuir para sociedades mais equitativas e igualitárias. 
Para que ocorra a transformação em sociedades mais justas, segundo Walsh (2010), é necessário partir do problema estrutural-colonial-racial e dirigir-se para a transformação das estruturas, instituições e relações sociais com a construção de condições radicalmente distintas, que é possível pela interculturalidade crítica. Uma prática política e participativa que se cruza com a relação estabelecida entre o saber e o ser, e que se preocupa com a exclusão, a negação e a subalternização ontológica e epistêmico-cognitiva dos grupos e sujeitos racializados; práticas de invisibilização, desumanização e de subordinação de conhecimentos que rompem com os privilégios de uns sobre outros, sendo necessário reconhecer e desnaturalizar as diferenças, as desigualdades que estruturam as sociedades.

Por isso, seu projeto educativo se constrói de mãos dadas com a decolonialidade como ferramenta que visualiza os dispositivos de poder como estratégias nas relações de saber, ser, poder e da própria vida radicalmente distintas a criação de compreensões e condições que articulam e fazem dialogar com as diferenças num marco de legitimidade, dignidade, igualdade, equidade e respeito, ao mesmo tempo mostrando que existem outros modos legítimos de ser e estar no mundo, em que seja necessário

\footnotetext{
"pensar a partir de" [a] condição "ontológico-existencial-racializada dos colonizados, apontando novas compreensões próprias da colonialidade do poder, saber e ser e a que cruze o campo cosmogônico territorial, mágico e espiritual da própria vida" (WALSH, 2009, p.28).
}

Para tanto, compreendemos que a interculturalidade crítica e a decolonialidade são projetos, processos e lutas que se entrecruzam conceitualmente e pedagogicamente, alentando forças, iniciativas e perspectivas éticas que fazem questionar, transformar, sacudir, rearticular e construir uma pedagogia decolonial.

\section{Na aldeia não tem toda aquela cobrança}

[...] quando a gente estuda na aldeia, a gente estuda do modo que a gente quer aprender, não tem a Matemática, Física, Química, igual na cidade, na aldeia não tem toda aquela cobrança e quando a gente chega na cidade a gente sente [...] quando comecei a estudar não sabia pesquisar em um livro didático [...] Quando penso nas desistências na universidade, penso no ensino básico nas aldeias, pois ele estudou na forma como a comunidade dele queria e falta professores formados, recursos didáticos para o aluno realmente aprenda e isso faz com que o indígena quando chega na universidade encontre essas dificuldades e acaba desistido do curso (Nayara). 
A mônada "Na aldeia não tem toda aquela cobrança" traz elementos de reflexão sobre a falta de uma política expressiva de educação escolar indígena na região do sudeste do Pará e na sua aldeia.

Em relação ao ensino superior na região foco da pesquisa, Cajueiro (2008) traz um estudo anterior à Lei $\mathrm{n}^{\circ}$ 12.711/2012, mostrando que a região Norte é o local onde se concentra a maior parte da população indígena do país, formando $16 \%$ da população total da região; embora o estado do Pará tenha sido o primeiro em se tratando dos cursos de Licenciatura Intercultural Indígena, eram tímidas as ações afirmativas voltadas ao acesso ao ensino superior em relação aos outros estados brasileiros. Se analisarmos as mônadas apresentadas acima, perceberemos que elas nos trazem elementos relacionados às conquistas a serem alcançadas em relação ao ensino fundamental e médio nas aldeias, avançando no processo de escolarização cada vez mais crescente nos povos indígenas do Brasil.

Outro elemento que podemos destacar relaciona-se com a reflexão entre o hiato existente tanto relacionado ao que é assegurado legalmente no tocante à educação escolar indígena e sua efetivação nos diversos territórios indígenas, quanto relacionado à educação especifica, bilíngue e multicultural existente em algumas comunidades de povos indígenas, os quais, ao entrarem na ordem cognitiva educacional da universidade, não são consideradas distintas trajetórias de formação, implicando ser um espaço de estranhamentos, por não dialogar com formas e tempos próprios de organização e produção de saberes, conhecimentos, valores e culturas de diversos povos.

\section{Estudar}

[...] Eu dizia pros meus filhos e irmãos, todo mundo tem que estudar. Vocês não estão vendo que a cada ano que passa as coisas estão mudando? Vão criando leis, [...] tirando o direito do índio de ser índio [...] que não tenha direito [...] minha visão é, falo para meus filhos, falo para a comunidade onde eu chegar eu falo: vocês estudam, estudem pra vocês saberem qual o direito, quando tiram um pedacinho das nossas terra, quando tiram uma árvore da nossa terra. Por que a terra é a nossa mãe, o igarapé nosso pai que nos criou, do igarapé nós se alimenta, da terra se alimenta. [...] então vocês têm que saber falar numa reunião, tem que ter argumento, tem que ter visão, por isso que quero que vocês estudem, que cada índio seja um advogado, um agrônomo, seja um médico, uma professora, um juiz, a nossa vontade é de chegar a esse patamar de ensino pra comunidade. De não depender de pagar advogado [..] porque muito branco, nem todos, mas alguns vem com má intenção pra comunidade. Nós temos que estudar voltado para nossa comunidade, aprender conhecimento do branco e aplicar dentro da comunidade e todo indígena ele tem que ter o mesmo pensamento, 
estudar mas não deixar de praticar sua cultura, nem seus costumes e a universidade tem que respeitar, por que o índio era proibido de estudar da quinta série em diante, era só até quarta série, a quinta não podia, por que tinha que ser dominado pela FUNAI, né? [...] É isso que a gente quer, que o índio estuda, que ele aprenda dar valor no que tem na terra, dar valor na mata, no rio, porque tantas ervas medicinais que nós tem, tantas orquídeas... Quem tá formado pra cuidar dessa área? Quem é o biólogo, quem vai ser o biólogo, pra cuidar dos animais doentes? Como que nós sabe que o habitat dessas aves não é mais aqui?(...) do viado? Por quê? Nós só imaginamos! Foi embora por causa do barulho do trem? Foi o rio que secou? Por que secou? Que tipo de combustível é valioso? A fumaça polui o ar? $\mathrm{O}$ minério vai ate a onde, quantos quilômetros? [...] a Vale trás trinta e quatro advogados, quando vem conversar com a gente, sendo que a gente não tem um (Kátia).

Na mônada "Estudar", a narradora nos remete a pensar sobre a importância do acesso à universidade como uma das formas de compreensão da igualdade nos projetos societários e assim melhor subsidiar o diálogo na sociedade evolvente com seus projetos de luta e permanência em seus territórios. O filósofo e educador Baniwa contribui nesse campo de discussão quando enaltece que:

\begin{abstract}
A escolarização em todos os níveis passou a ser uma das principais bandeiras de luta dos povos indígenas. Esta opção estratégica se deve ao fato de que os povos indígenas consideram a formação escolar como um dos instrumentos importantes de luta pela defesa e promoção dos direitos indígenas, na medida em que permite a apropriação dos conhecimentos e tecnologias do mundo moderno capazes de contribuir para a melhoria das condições de vida em suas aldeias e como possibilidade de participação política, que irá contribuir para formulação e implementação de políticas públicas desejadas. Ou seja, a formação escolar, particularmente o ensino superior, é considerada como uma possibilidade de acesso à cidadania e recuperação da autonomia étnica, no contexto do mundo moderno e dos Estados nacionais (BANIWA, 2009, p. 199).
\end{abstract}

No entanto, pensando em formas de dominação, novamente nos remetemos à interculturalidade sistêmica (WALSH, 2012), indagando se a entrada de povos originários na universidade é pensada de forma a modificar a exclusão e processos de dominação há anos vivenciados ou somente como uma estratégia do governo de compensação a esses povos, permitindo por dispositivos legais somente seu acesso, sem garantir sua permanência, sem reconhecer seus conhecimentos ancestrais como tecnológicos e científicos, sem homogeneizar as diferentes especificidades de cada povo ali presente e sem, ao menos, informarem os educadores da presença de educandos/as 
indígenas em suas turmas, negando a importância e afirmando sua política de inclusão, mantendo o eurocentrismo como única perspectiva de conhecimento.

A burocracia em conseguir acesso ao auxilio estudantil e moradia, extremamente necessários à continuidade dos estudos, também pode ser analisada como uma política que faz parte da interculturalidade funcional como uma das formas do Estado assumir a nova lógica multicultural do capitalismo global, ou seja:

una lógica que reconoce la diferencia, sustentando su producción y administración dentro del orden nacional, neutralizándola y vaciándola de su significado efectivo, volviéndola funcional a este orden y, a la vez, a los dictámenes del sistema-mundo y la expansión del neoliberalismo [...]. En este sentido, el reconocimiento y el respeto a la diversidad cultural se convierten en una nueva estrategia de dominación, que apunta no a la creación de sociedades más equitativas e igualitarias, sino al control del conflicto étnico y la conservación de la estabilidad social con el fin de impulsar los imperativos económicos del modelo (neoliberalizado) de acumulación capitalista, ahora "incluyendo" a los grupos históricamente excluidos en su interior (WALSH, 2010, p. 03).

Nesse sentido o multiculturalismo, assume a existência das diversas culturas sem no entanto modificar suas estruturas de poder e dominação, orientando suas práticas baseadas em um projeto de capitalismo neoliberal, relacionado á lógica multicultural do capitalismo que reconhece as diferenças e as neutraliza dentro de uma estratégia de dominação.

\section{Quando ligo a lâmpada}

[...] Quando venho para Marabá, fico na casa de um casal amigo, as vezes quero estudar a noite, e coloco na lâmpada, mas fico com vergonha pois sei que não sou eu que vou pagar. Na minha casa em Itupiranga também é difícil estudar, pois a casa é pequena e são muitas pessoas, quando ligo a lâmpada a noite ilumina tudo e está todo mundo dormindo na rede e eu me pergunto: Meu Deus do céu como é que estudo? Não é fácil. [...] Do que aprendo aqui na universidade eu levo muito a parte do estudo... [...] nos temos que ir atrás. [...] eu não quero abandonar a minha aldeia (Raquel).

\section{A bolsa moradia}

Aí tentei uma bolsa pela UFPA pra moradia. Conseguimos. Só que demorou a sair. Antes de sair, conheci um rapaz que fazia direito e é indígena, não conhecia ele. A mãe da minha cunhada trabalha aqui, ela me ligou e falou que tinha um indígena que queria falar comigo. E falou que o governo tinha aprovado uma bolsa para a indígena e quilombola, 
e falou para entrar no site e me inscrever. Esse rapaz foi tipo um enviado para mim, por que nem eu e tia Raquel já estávamos sem expectativas de continuar, por que não estava trabalhando e me orientou os procedimentos, me levou na FUNAI e o documento que era para ser enviado pelo correio, foi enviado pela mulher dele que estudava em Belém, e deu certo. Orientei a tia Raquel, fomos aprovadas e confirmamos nossa permanência no curso (Nayara).

As dificuldades para saída da aldeia, desde o processo de inscrição ao recebimento da primeira bolsa - que demora em torno de três meses - são evidentes nas mônadas “Quando ligo a lâmpada" e "A bolsa moradia" indicam as inúmeras dificuldades relacionadas aos desafios que enfrentaram em acessar essas informações, conhecer os prazos, os procedimentos, os documentos necessários e sobreviver na cidade sem bolsas de estudos entre o período de sua efetivação devido aos trâmites burocráticos da universidade. Apontam a necessidade de uma moradia indígena a estes homens e mulheres oriundos de diversos povos da região, com diferentes culturas e distâncias entre as aldeias e universidade.

Portanto, faz-se necessário visualizar possíveis alternativas, ancoradas em práticas dialógicas, que respeitem essas diferenças e atentem às demandas colocadas aos vários grupos distintos que ocupam esse espaço, iniciando um diálogo propositivo entre a instituição de ensino e os/as sujeitos/as, a fim de efetivar uma melhor acolhida nesse novo lugar de direito ao qual ocupam.

Edgardo Lander (2005), ao escrever sobre ciências sociais, saberes coloniais e eurocêntricos, também nos remete a um processo de naturalização que ocorre nas relações sociais, nas quais as chamadas sociedades modernas utilizam-se de expressões que dificultam o combate ao neoliberalismo, que deve ser compreendido além de uma teoria econômica, mas como um discurso hegemônico de modelos de civilização que moldam os valores básicos da sociedade no que diz respeito ao ser, à natureza, ao progresso, conhecimento e ideal de boa vida. Ou seja, criam-se modelos únicos desejáveis e possíveis, com uma única narrativa histórica, como conhecimento objetivo, científico e universal. A dominação do discurso hegemônico invisibiliza e aniquila as contradições existentes dentro da sociedade é possível identificar duas dimensões: a primeira, referese às sucessivas separações ou partições do mundo "real" que ocorrem historicamente na sociedade ocidental e a forma como é construído o conhecimento sobre as bases desse processo de sucessivas separações. A segunda dimensão é a forma como se articulam os 
saberes modernos com a organização do poder, especialmente as relações coloniais/imperiais de poder constitutivas do mundo moderno.

\section{Dificuldades}

E entrei na Universidade, só que foi um choque muito grande. Pensei que não ia dar conta. Quase que entrei em desespero porque era muito difícil. Ainda mais que no ensino médio não temos assim um ensino de qualidade, porque muitas das coisas que é preciso ver. Porque vai ser necessário no ensino superior, a gente não ver direito. Principalmente quando se vai fazer o curso de Direito. A gente tem que ter uma base na área de filosofia muito grande. Porque, praticamente, o curso vai decorrer baseado nesses filósofos. Então minha dificuldade foi essa. Mas só que depois a gente vai se esforçando, se adaptando. [...] Minha grande dificuldade é apresentar trabalho. [...] Não sei, parece que bate o nervosismo. Tenho medo de errar. Sei que muitas pessoas nem prestam atenção, mas a gente coloca na mente que eles vão criticar, que vai errar. [...] Apresentei poucos trabalhos na minha vida durante meus estudos. [...] Eu não deixo de apresentar meus trabalhos. Eu apresento, tem que apresentar. Mas já tô superando isso. Porque na ultima apresentação eu tive mais autocontrole (Nayane).

A mônada "Dificuldades" ressaltam a questão do estranhamento em relação à universidade, o qual relaciono com uma colonialidade do saber e do ser, em que o conhecimento dos "outros", o conhecimento "tradicional" dos pobres, dos camponeses, não apenas era considerado não pertinente, como também um dos obstáculos à tarefa transformadora do desenvolvimento (LANDER, 2005).

A colonialidade do saber e o racismo epistêmico aos quais as mônadas nos remetem, evidenciam que não importa as diferenças de culturas, de linguagens, de compreensão de mundo: essas não são respeitadas pelas práticas oficiais, mesmo que imbuídas em um discurso de respeito às diferenças e diálogo entre culturas. Os mecanismos institucionais invisibilizam essas diferenças $e$ as forçam a um enquadramento, ou seja, homogeneizam essas diferenças e saberes, inclusive criando dispositivos de culpabilização para que não se sintam capazes de ocupar esse espaço.

Dessa forma, o processo formativo na universidade, mesmo que muita vezes não dialogue com questões sensíveis à vida das estudantes indígenas e nem com as diferenças entre os povos ali representados, negando o questionamento ao seu caráter de universalidade ancorado a somente uma forma de conhecimento baseado em cânones ocidentais, é um local de resistências, evidenciado no protagonismo feminino indígena imposto aos desafios da permanência, nas identidades contrastivas, em que embora o... 
[...] meio acadêmico ensina 'verdades' que contrapõem ou negam os conhecimentos e valores tradicionais de nossos povos e isso gera uma sensação de mal-estar difícil de administrar, assim como um conflito de lealdades. Muito tempo é despendido para equilibrar a convivência com diferentes 'verdades', que acarreta em forte relativismo de nossas concepções sobre valores e conhecimentos tradicionais. Esse relativismo é, por vezes, perverso, pois culmina na perda de nossa identidade, no papel de membros de grupos étnicos distintos, na medida em que tudo o que nos fazia Baniwa é posto em questionamento, e esse, do ponto de vista de nosso povo, é perigoso (BANIWA, 2009, p. 36).

$\mathrm{E}$ as identidades, se formam em relação ao que o diferencia do outro, esse outro letrado, que sabe se articular pela oralidade acadêmica e como vão entrando no mundo da pesquisa, da investigação criando suas estratégias de lutas e resistências dentro desse espaço antagônico e causador de choques entre realidades e conhecimentos.

\section{Indígena genérica}

[...] Eu não me acho inteligente, pois custo a entender as coisas. [...] Os colegas da escola no ensino fundamental e médio, não queriam fazer trabalho comigo pois diziam que os indígenas eram burros, aqui na universidade quando entrei, não me identificava como indígena, os colegas não perceberam, depois de um tempo, professores entravam na sala e dizia: Nós temos uma indígena na sala, eles olhavam entre si perguntando quem era, mas não me identificavam, eu ficava calada, e pensava será que eles sabem que sou indígena? Mas foi tranquilo. Depois me identifiquei, eles disseram que não parecia com índia. No Maranhão me chamavam de indígena genérica, de índia falsa. Me acho parecida com meu pai, os traços.[...] eu me acho desinteressada dos estudos, vejo que quando vou fazer uma prova não me sinto segura, eu estudo, estudo, mas me sinto muito fraca. Não tenho computador em casa, eu leio os textos, mas na hora que vou apresentar os seminários e fazer a prova, sou péssima. As pessoas até riem de mim quando é o meu dia de apresentar (Raquel).

A colonialidade do ser (WALSH, 2008, 2009, 2013; MALDONADO-TORRES, 2008; GROSFOGUEL, 2009; QUIJANO, 2010) aparece nas mônadas que refletem sobre preconceitos "Indígena genérica" e "Um índio chega à universidade", nas quais se registram o racismo experenciado no espaço acadêmico, evidenciado na cristalização de um estereótipo universal aos pertencentes dos povos originários, ligado à colonialidade do ser.

Com base nisso, fazemos questionamentos relacionados aos distintos lugares de fala e de trajetórias escolares que compõem essas mulheres e se estes são respeitados ao entrarem na universidade.

Talvez esses aspectos possam ser fundantes para se pensar as diferenças entre os povos que ocupam aquele espaço, refletindo sobre essas diferenças pela presença dos 
diversos povos indígenas na universidade, que poderiam assinalar como uma possibilidade de romper com a homogeneização, tendo como desdobramentos a possível construção de política de ensino superior indígena que reconheça e trabalhe nos mais diversos setores com essas particularidades.

Boaventura de Souza Santos, professor português da Universidade de Coimbra, nos ajuda a pensar a questão da igualdade na luta coletiva e, levando em consideração as diferenças entre as mulheres Guajajara e a cacica Kátia, todas adotaram estratégias de sobrevivência nesse mundo que as cerca, onde são diferentes pelas suas trajetórias, mas iguais no engajamento pela luta por território e na garantia de seus direitos.

Assim, visualizamos a diversidade como um desafio às universidades, vislumbrando a necessidade, como assinala Candau (2009), de perceber a existência de práticas interculturais, diferenciando a interculturalidade crítica da funcional, e se são utilizadas como estratégia de coesão social, assimilando os grupos subalternizados a uma cultura hegemônica ou como construtivas de democracia, capazes de construir novas relações e contribuindo com os projetos societários desses povos (WALSH, 2008; 2006; $2012 ; 2010)$.

Para uma melhor compreensão acerca dos conceitos de igualdade, desigualdade e diferença, bem como seus usos, Candau (2009) contribui ao entendimento que não se deve refutar igualdade a diferença e sim desigualdade e a padronização de formas de comportamentos, da mecanização de padrões. A esta forma de compreensão em que as diferenças devem ser respeitadas, Santos (2003) complementa na compreensão de igualdade e diferença, quando diz que "temos o direito de ser iguais quando a diferença nos inferioriza; temos o direito a ser diferentes quando a igualdade nos descaracteriza" (SANTOS, 2003, p. 56).

É possível afirmar que a entrada na universidade causa impactos, tanto a essas mulheres como à própria instituição, que vai sendo mobilizada a pensar os desafios postos a essa presença.

\section{Um índio chega à universidade}

Quando um índio chega à universidade, é visto de forma diferente, "esse índio ai ô, eu olho pra ele e parece que não sabe de nada". Mas não sabem a dificuldade, por isso estou pedindo hoje professores qualificados, preparados, para preparar meu povo, para quando ele for para uma faculdade ele saiba onde ele está estudando, onde ele está pisando, ele vai ter visão, ele vai falar. [...] Então eu fico muito feliz quando um índio se forma, mas o índio voltado pra sua comunidade, não o índio que quer ser o "branco", que quer morar na rua, casa 
mansão, tem direito?! É um direito! Mas por que não volta pra sua comunidade, não olha seu povo, não ajuda? (Kátia).

\section{Dentro da nossa casa}

Hoje nós temos esse pensamento, esse cuidado de trazer a universidade pra dentro da nossa casa, nos temos esse cuidado, nós queremos que o índio ele estude aqui dentro, que ele aprenda e sirva aqui dentro. O nosso medo é que o índio vá estudar e se envolva pra lá, e não é por preconceito, e sim, o cuidado em multiplicar o povo, não queremos mais que o índio case com cupém, para fortalecer nossa cultura. (Kátia)

A mônada "Um índio chega na universidade" está ligada ao que é colocado acima, sobre o limites e desafios entre esses dois mundos, ligada a projetos de futuro, às preocupações relacionadas a emprego, ao retorno à aldeia depois de formadas. Desafios impostos a essas mulheres, mas que, possivelmente, se os currículos de curso dialogassem com suas realidades, elas estariam desenvolvendo projetos societários e, consequentemente, sofrendo menos preocupações de futuro. Do mesmo modo, se as atividades de extensão dialogassem com as comunidades às quais pertencem essas mulheres, também seria uma forma de manter a dialogicidade entre dois projetos de formação, em que um aprenderia com o outro, como aponta a mônada "Dentro da nossa casa". Visto que...

[...] esse despertar para a academia não é movido por um interesse especulativo, posto que emerge das dificuldades enfrentadas pela comunidade, mas busca a firmação dos grupos como iguais e diferentes aos não indígenas, desde que não espojados de sua identidade indígena e nem inferiorizados. Busca-se a promoção dos saberes dos grupos, iniciação nos saberes da ciência não indígena, sem deixar de desenvolver-se no saber tradicional. No relacionamento baseado na qualidade intercultural, é justa a aliança buscada pelos indígenas na universidade, para mudar a forma com que eles costumam ser analisados pelos não indígenas e para serem reconhecidos como sujeitos de saber e de palavra (CHAMORRO, 2009. p. 17).

Embora ainda predominem muitos silenciamentos em relação a homens e mulheres indígenas ocupando espaços nas universidades, ocorre um movimento recente protagonizado por esses guerreiros e guerreiras que impulsionam a discussão em torno da construção de políticas de ensino superior mais respeitosa. A essa ação, alguns educadores e técnicos presentes em universidades brasileiras vão se colocado ao lado dos povos invisibilizados pelo sistema, vislumbrando-se assim indícios de trabalhos que dialogam com suas necessidades, construindo aproximações com uma pedagogia mais decolonial. 
Portanto, desvelar os processos de colonialidade do pensamento, do ser e do saber implica a construção de outros processos de conhecimentos, para os quais ainda não existem modelos. Entretanto, as leituras do grupo de estudos modernidade/ colonialidade ${ }^{3}$ indicam caminhos que contribuem para a verificação da estrutura opressora do tripé colonialidade (do poder, saber e do ser), conforme aponta a professora Luciana Ballestrin (2013).

Dentro desse processo colonizador e suas implicações, o enquadramento a esse modelo de pensamento e comportamento universal na academia não se refere somente aos povos originários, mas estende-se como forma de dominação possível a qualquer estudante na universidade, a qualquer saber que se diferencie do poder circunscrito universal, dominante e a serviço de políticas neoliberais.

Porém, no caso específico desses estudantes oriundos dos povos originários, assinalamos que o desafio posto às universidades está além das políticas afirmativas, que contribuem para entrada de indígenas nas universidades brasileiras, ou ligadas somente as bolsas de apoio e permanência estudantil, em que não basta disponibilizar cotas, mas complementá-las com projetos e programas que possibilitem o acompanhamento dos acadêmicos indígenas, mantendo-os em contato com suas comunidades durante o estudo, além de ações formativas dentro das instituições que reduzam as práticas de racismos e humilhação aos quais são vitimas dentro de universidades (BANIWA, 2017).

Para Nelson Maldonado-Torres (2008), em sua reflexão crítica sobre os cânones da filosofia europeia, aponta que esses tendem a converter a Europa no centro epistêmico do mundo, contribuindo para o eurocentrismo ontológico, que desumaniza todos os que se diferenciam da norma cristalizada de ser. Dessa forma compreende ser necessária uma proposta radical da geopolítica decolonial, que potencialize as epistemologias não europeias.

Essa dupla ação entre reconhecer e homogeneizar, fixando estereótipos, pode ser compreendida como presença significativa de um racismo epistêmico e institucional, no qual se reproduz a relação de hierarquias entre povos dentro da universidade e da sociedade.

\footnotetext{
${ }^{3}$ Iniciado na década de 1980, nos Estados Unidos com o texto "Colonialidad y modernidade-racionalidad", do sociólogo peruano Anibal Quijano, momento em que é inserindo na América Latina nos estudos póscoloniais. O grupo hoje é formado por Walter Mignolo (Argentina), Catherine Walsh (Equador), Zulma Palermo (Argentina), Anibal Quijano (Peru), Nelson Maldonado-Torres (Porto Rico), Santiago Castro Gomes (Colômbia), Ramón Grosfoquel (Costa Rica), Arturo Escobar (Colômbia), Edgardo Lander, (Venezuela), Henrique Dussel (México) e outros pensadores.
} 
Maldonado-Torres (2008) indaga-se, a partir da leitura de Quijano, sobre quem vem primeiro: a relação de raça ou o capitalismo? Na compreensão de Quijano, elas são indissociáveis. $\mathrm{O}$ autor acrescenta que entende a raça como a formação fundante para se pensar o racismo, que nasce no mundo moderno e que se alarga para a questão de gênero, criando-se assim outras formas de dominação.

Portanto, prefere utilizar um termo que se aproxime da naturalização entre diferenças humanas, naturalização das diferenças, só que uma naturalização hierárquica e ontológica, em que o outro não quer aparecer como ele mesmo, mas como outro, o que é tido como valorizado, como culto, como belo. Aponta algumas abordagens que, para ele, formam os três elementos da colonialidade: o corpo, numa relação de poder em que tanto pode ser inferiorizado como supervalorizado. A catástrofe metafísica ocorre no momento em que o corpo pode ser transformado na forma que é percebido. O segundo elemento seria a espiritualidade, dimensão em que o ser humano se contata com o outro, o outro diferente, o divino, mostrando que indígenas sofreram a catástrofe metafísica, quando se dizia que eles não tinham religião, que não têm dimensão metafísica para se conectarem com o outro. E o último, a língua, como forma de dominação aos que não tinham escritura alfabética, logo, os indígenas não eram seres humanos, não tinha a relação com a comunicação.

Logo, os povos originários que hoje se apresentam fugindo ao imaginário padrão, estabelecido como forma de dominação do nativo bruto, isolado em suas florestas, vivendo da caça e da pesca, falantes de língua maternas e portadores de uma cultura pura, sofrem preconceitos pelo imaginário do estereótipo indígena, de modo que deixamos de apreender com suas experiências outras formas de conhecimento.

Nesse sentido, nos interrogamos: será que os educandos pertencentes aos povos originários que fazem cursos específicos são "reconhecidos" como intelectuais portadores de direitos ou ficam à margem, como se fossem guetos dentro de um universo que não os reconhece e nem dialoga? São apensas reflexões as quais vemos relacionadas a formas de dominação e possivelmente dentro de uma interculturalidade sistêmica.

No entanto, é pertinente afirmar as resistências. Pois as protagonistas desta pesquisa afirmam-se guerreiras, construindo essa História indígena na universidade, enfrentando os percalços desse novo, rememorando suas trajetórias na universidade, construídas desde o início como atos de resistência e enfrentamentos, ao apropriarem-se de elementos de um saber pautado em tecnologias do mundo moderno e hierarquizado como ferramenta de diálogo, contribuindo para a melhoria das condições de vida de suas 
comunidades e, consequentemente, contribuindo para a reflexão e o avanço das políticas de ensino superior indígena nas universidades.

\section{Considerações finais}

Percebemos pelas memórias de experiências narradas os conflitos e tensões no âmbito acadêmico e que, de certa forma, ao serem narradas, contribuem para a construção de um futuro mais dialógico e respeitoso dentro do espaço acadêmico em relação à experiência de quem vive a universidade e tem o que falar sobre esse espaço, revelando as violências e tensões que se fazem presentes em seus corpos e em suas experiências. Ao mesmo tempo, mesmo com todas as contradições que vivenciam no espaço formal de construção de uma única forma de conhecimento, têm a responsabilidade de serem tradutores do que escutam, do que sentem, e transformar para o seu mundo o que lhe dá significado.

Dessa forma, a presença dessas mulheres pertencentes a povos originários protagoniza a reflexão necessária referente as práticas tidas como normais, forçando o desvelar de práticas de discriminação e racismo experienciadas por homens e mulheres pertencentes aos povos originários, não somente no espaço acadêmico como também pela imagem que aprisiona identidades e culturas, que visam moldar uma única forma de comportamento e estereótipos, provocando racismos epistêmicos que apagam a capacidade epistêmica "de certos grupos de pessoas. Pode basear-se na metafísica ou na ontologia, mas os resultados acabam por ser os mesmos: evitar reconhecer os outros como seres inteiramente humanos" (MALDONADO-TORRES, 2008, p. 79).

A escolha pela aproximação de modelos teóricos e metodológicos pautados no diálogo com o grupo modernidade e decolonialidade e autores como Benjamin produzem elementos no campo de ensino e desta pesquisa para repensar espaços históricos até então ocupados na construção de conhecimento, em grande parte, pela transposição de modelos eurocêntricos. Falam a partir da Europa para o mundo inteiro, sem dialogar com as especificidades dos diversos conhecimentos e espaços históricos distintos a este modelo de ciência, que impõem suas chaves de interpretações de entendimento das ciências como sendo única.

Mesmo de um lugar distante, existe um modelo de dominação europeu além da dominação territorial e econômica nos dias atuais, fazendo-se presente em um processo de colonização do saber, que não dialoga com outras formas de produções de 
conhecimentos - como, por exemplo, saberes dos povos originários e negros, que estão na fronteira das lutas sociais e políticas do seu tempo e são invisibilizados na produção de conhecimento e da história.

Portanto, concebemos a pesquisa realizada como uma pesquisa históricoeducacional em sentido dialético e de complementaridade, constituída de memórias narradas de um tempo e lugar não lineares, preenchido pelo agora, como nos faz lembrar Benjamin (2012) em uma de suas teses sobre história, ao falar sobre o salto do tigre ao passado na arena em que está sempre presente o dominador, e que nesse salto devemos salvar a herança dos oprimidos

Podemos perceber também, conforme Walsh (2009; 2010), a presença de distintas formas de interculturalidade, sendo a funcional a dominante, por fazer parte das políticas neoliberais, mas que devemos avançar para uma interculturalidade crítica, concebida como projeto político, social, epistêmico, ético e transformador do processo de colonização. Para a autora, a interculturalidade só terá impacto se for além de diálogos entre saberes, políticas e projetos educacionais, e se for assumida de forma crítica, como um processo de ação que procurem interferir na refundação de estruturas e ordenamentos sociais, que racializam, inferiorizam, e desumanizam embasados numa hierarquia de saber e de poder no sistema dominante. Nesse sentido, identificamos esta dominação nas rememorações das mulheres indígenas sobre a universidade.

A interculturalidade crítica talvez seja uma prática antiga dos povos originários, pois, há muitos anos, mesmo sofrendo pelos jogos de poder, dialogam com saberes ancestrais e saberes impostos. Portanto, suas impressões sobre o espaço formativo dão caminhos a reflexões sobre essas diferenças e assim promovem uma formação intercultural e decolonizada proporcionando aprendizagens mútuas significativas.

Esse exercício de olhar a outra, como processo de reconhecimento, respeito e diálogo, não nos foi ensinando. Como seres colonizados e também colonizadores, aprendemos a valorizar, reforçar e até mesmo repetir o conhecimento de fora; repetir padrões de comportamentos racistas, de opressão de gênero, étnicos e raciais sem questioná-los, de certa forma naturalizando as diferenças e supostas hierarquias entre povos, repetindo formas de dominação presentes desde os processos de colonização.

Compreendemos que as próprias mônadas trazem apontamentos nos desafiando a olhar com estranhamentos a forma como ocorrem as políticas de permanência na universidade, e que o logos produzido nas universidades, ainda estão, embasados em uma hierarquia de saber e de ser gerando mais preconceitos e não contribuindo a uma 
proposição mais dialógica e respeitosa com mulheres pertencentes a povos originários, que ainda no tempo presente, além das violências sofridas na universidade, lutam diariamente em diferentes formas pelo fortalecimento e manutenção de seus territórios e valoração de seus saberes.

A luta pelo acesso à universidade, pelas ações afirmativas, democratiza o acesso, movimenta o público na universidade, "colore os auditórios", traz a diversificação da cultura, da história, forçando a repensar o acesso e permanência além de bolsas; ou somente currículos dos cursos, que ainda são pautados numa lógica colonial, que invisibiliza outros saberes, perpetuando uma desigualdade entre os presentes e, com isso, colonizando mais uma vez saberes e seres.

\section{Referencias}

BALLESTRIN, Luciana. América Latina e o giro decolonial. Revista Brasileira de Ciência Política, Brasília, n 11, 2013, pp. 89-117.

BANIWA, Gersem. A lei das cotas e os povos indígenas: mais um desafio para a diversidade. Revista Fórum, São Paulo, n. 119, p.18-21, 19 set. 2013. Semanal. Disponível em: <https://www.revistaforum.com.br/digital/119/ok-a-lei-das-cotas-e-ospovos-indigenas-mais-um-desafio-para-a-diversidade/>. Acesso em: 21 abr. 2017.

BENJAMIN, Walter. O Narrador: considerações sobre a obra de Nikolai Leskov. In: Magia e técnica, arte e política: ensaios sobre a literatura e história da cultura. $2^{\mathrm{a}}$ ed. São Paulo: Brasiliense, 2012. p.197-221 (Obras Escolhidas v. 1).

BENJAMIN, Walter. Origem do drama trágico alemão. Ed e Trad. João Barreto. Belo Horizonte: Autêntica Editora, 2011.

BENJAMIN, Walter. Passagens. Belo Horizonte: Ed. da UFMG/ Imprensa Nacional do Estado de São Paulo, 2007.

BENJAMIN, Walter. Sobre o conceito de história. In: Magia e técnica, arte e política: ensaios sobre a literatura e história da cultura. 2 ed. São Paulo: Brasiliense, 2012 (Obras Escolhidas v. 1).

BRASIL. Lei $\mathrm{n}^{\mathrm{o}}$ 12.711, de 29 de agosto de 2012 (Lei de Cotas: dispõe sobre o ingresso nas universidades federais e nas instituições federais de ensino técnico de nível médio).

CANDAU, Vera Maria. Educação Intercultural na América Latina: entre concepções, tensões e propostas. Rio de Janeiro: 7 Letras, 2009.

CHAMORRO. Graciela. la calidad intercultural: desdoblamientos reacción a la conferencia pronunciada por la dra. maría elena gonzález, de la universidad de la frontera, temuco, Chile. In: NASCIMENTO, Adir Casaro (Org.). Povos indígenas $e$ sustentabilidade: saberes e práticas interculturais nas universidades. Campo Grande: UCDB, 2009. 
FRANÇA, Cyntia Simioni. O Canto da Odisseia e as Narrativas Docentes: dois mundos que dialogam na produção de conhecimento histórico educacional. Tese (Doutorado) Faculdade de Educação, Universidade Estadual de Campinas, Campinas. 2015.

GAVIÃO, Kátia. Entrevista concedida à Tatiana de Oliveira Santana. Marabá, Pará. 01 de março de 2016.

GROSFOGUEL, Ramón. Para descolonizar os estudos da economia política e os estudos pós-coloniais: transmodernidade, pensamento de fronteira e colonialidade global. In: SANTOS, Boaventura de Sousa; MENESES, Maria Paula (Orgs.). Epistemologias do Sul. Coimbra -Portugal: Almedina, 2009, p. 383-417.

GUAJAJARA, Nayane. Entrevista concedida à Tatiana de Oliveira Santana. Marabá, Pará. 20 de fevereiro de 2016.

GUAJAJARA, Nayara. Entrevista concedida à Tatiana de Oliveira Santana. Marabá, Pará. 21 de fevereiro de 2016.

GUAJAJARA, Raquel. Entrevista concedida à Tatiana de Oliveira Santana. Marabá, Pará. 21 de fevereiro de 2016

LANDER, Edgardo et al. A colonialidade do saber: eurocentrismo e ciências sociais. Perspectivas latino-américanas. Buenos Aires: CLACSO, 2005.

LUCIANO, Gersem José dos Santos. Novo Desafio para as Organizações Indígenas e Indigenistas no Brasil. In: SMILJANIC, Maria Inês; PIMENTA José; BAINES Stephen Grant. Faces da indianidade. Curitiba : Nexo Design, 2009.

MALDONADO-TORRES, Nelson. A topologia do ser e a geopolítica do conhecimento. Modernidade, império e colonialidade. Revista Crítica de Ciências Sociais, n. 80, p. 71$114,2008$.

PAIM, Elison Antonio. Professoras: Narradoras de memórias e experiências do trabalho em escolas multiseriadas em Palmitos/Santa Catarina. Revista Horizontes, v. 31, n.2, p 89-98, jul./dez, 2013a.

PAIM, Elison Antonio. Rememorações de professores de história: Expectativas quanto a formação inicial. Fóruns Contemporâneos de Ensino de História no Brasil, 2013.

ROSA, Maria Inês Petrucci. Currículo e narrativa: potencialidades das mônadas para uma outra compreensão dos acontecimentos educativos. In: MACEDO, Elizabeth; MACEDO, Roberto Sidnei; AMORIM, Antonio Carlos (organizadores). Discurso, texto, narrativa nas pesquisas em currículo. Campinas, SP: FE/UNICAMP, 2009. (E-book GT Currículo).

SANTOS, Boaventura de Sousa. Reconhecer para libertar: os caminhos do cosmopolitanismo multicultural. Rio de Janeiro: Civilização Brasileira, 2003. 
WALSH, Catherine. Interculturalidad crítica y educación intercultural. Construyendo interculturalidad crítica, p. 75-96, 2010.

WALSH, Catherine. Interculturalidad y (de)colonialidad: Perspectivas críticas y políticas. Visão Global, Joaçaba, v. 15, n. 1-2, p. 61-74, 2012.

WALSH, Catherine. Interculturalidad, Estado, sociedad. Luchas (de)coloniales de nuestra época. Quito: Universidad Andina Simón Bolívar: ABYA YALA, 2009a.

WALSH, Catherine. Interculturalidad, plurinacionalidad y decolonialidad: las insurgencias político -epistémicas de refundar el Estado. Tábula Rasa, Bogotá, n. 9, p. 131-152, 2008.

WALSH, Catherine. Interculturalidade crítica e pedagogia decolonial: in-surgir, re-existir e re-vivir. In: CANDAU, Vera Maria Ferrão (Org.). Educação Intercultural na América Latina: entre concepções, tensões e propostas. Rio de Janeiro: 7Letras, 2009, p. 12-42.

WALSH, Catherine. Lo pedagógico y lo decolonial: entretejiendo caminhos. In.:

Pedagogías decoloniales: prácticas insurgentes de resistir, (re)existir y (re)vivir. Tomo I. Quito, Ecuador: Ediciones Abya-Yala, 2013, p. 23-68.

WALSH, Catherine. Interculturalidad y (de)colonialidad: diferencia y nación de otro modo. In: MAGALHÃES NETO, Hamilton (org). Desarrollo e interculturalidad, imaginario y diferencia: la nación en el mundo andino. Río de Janeiro: Academia de la Latinidad, 2006, p. 27-43.

\footnotetext{
${ }^{1}$ Universidade Federal do Sul e Sudeste do Pará. Universidade recentemente criada na região Norte do Brasil, bem como palco de uma transição de recursos humanos e políticos entre a nova universidade e a atual UFPA.

${ }^{2}$ Três mulheres do povo Guajajará e uma cacica do Povo Akrankikatejê.

${ }^{3}$ Estima-se que em 1500 viviam cerca de 10 milhões de pessoas de diversos povos originários em seus respectivos territórios, onde hoje é o Brasil. Apesar de imensa riqueza humana pela diversidade de mais de 1400 povos originários com suas línguas, suas organizações sociais, culturais e políticas, seus conhecimentos, suas trajetórias históricas com seus passados e projetos de futuro, todos e tudo foram apreendidos pelo olhar colonizador como uma massa homogênea a qual foi atribuído o termo genérico "índios". Tal termo, no entanto, se mantém até hoje, mediante uma polifonia de significados, no campo de enunciação e negociação, em que o sentido positivo dado pelos indígenas contemporâneos confronta-se com o sentido negativo historicamente atribuído a eles. Dito isto, fazemos a opção em utilizaremos os termos índios e indígenas para se referir aos diversos povos originários no Brasil, sempre considerando a perspectiva dos próprios indígenas (Nascimento. 2009).

${ }^{4}$ Salientamos que as mônadas só foram publicadas após consentimento das mulheres indígenas que participaram da pesquisa.
} 